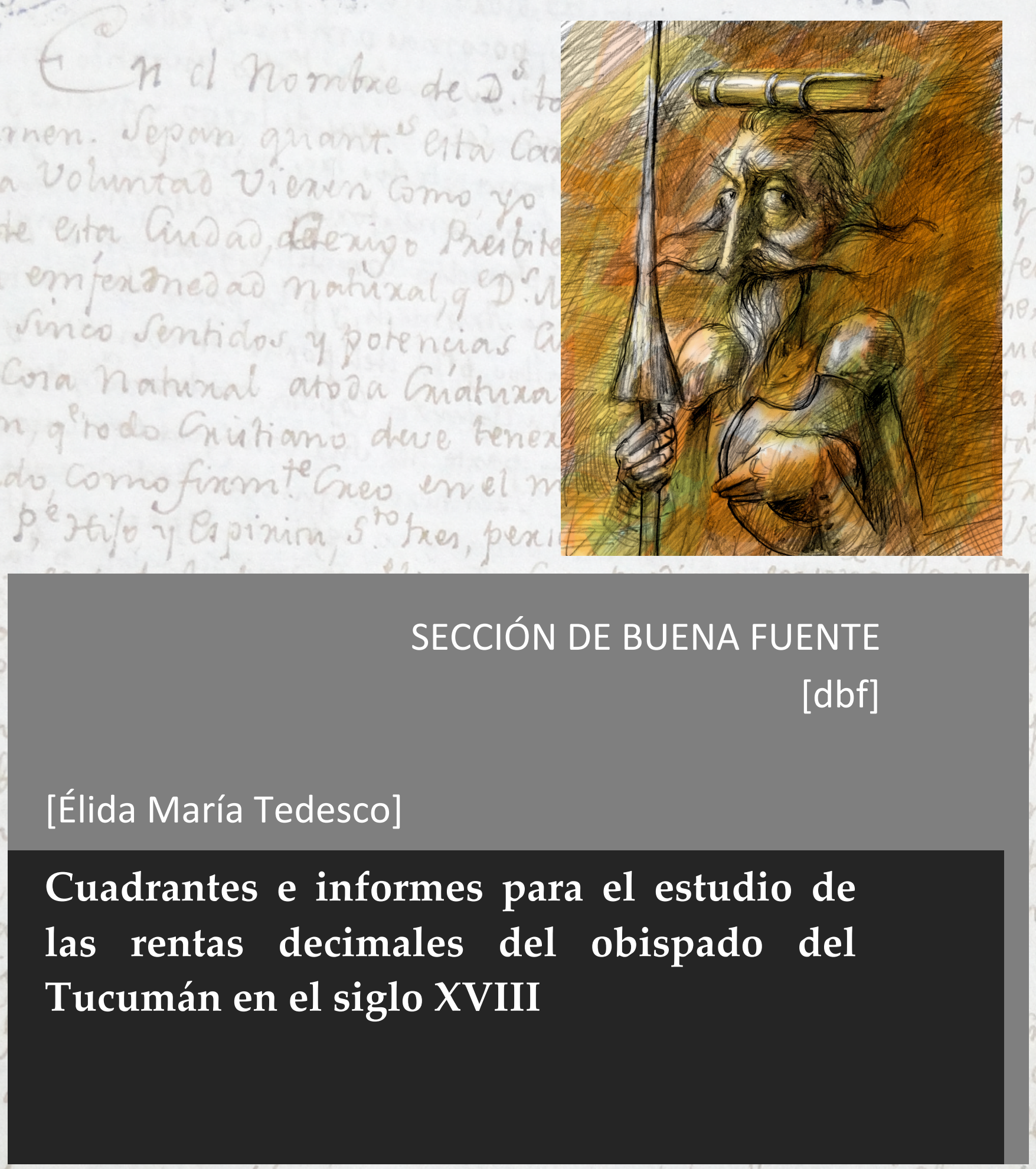

prohistoria a ño XIX, núm. 25 - jun. 2016 


\section{Cuadrantes e informes para el estudio de las rentas decimales del obispado del Tucumán en el siglo XVIII*}

\section{Cuadrantes and Reports for the Study of Income Decimal Bishopric of Tucumán in the Eighteenth Century}

\section{ÉLIDA MARÍA TEDESCO}

\section{Resumen}

Este trabajo analiza las características, posibilidades y limitaciones de la documentación decimal de la catedral de Córdoba, obispado del Tucumán, correspondiente al siglo XVIII. En particular, los informes sobre los montos de los ingresos decimales y su distribución, elaborados por los cabildos por exigencia de la Corona, en el marco del avance fiscal y financiero borbónico sobre las rentas de las iglesias americanas.

\section{Palabras clave}

Diezmos - Fuentes cuantitativas - Borbones Córdoba - siglo XVIII

\begin{abstract}
This paper analyzes the characteristics, possibilities and limitations of the decimal documentation of the cathedral of Cordoba (bishopric of Tucuman) for the eighteenth century. In particular, reports on the amounts of decimal income and its distribution prepared by the councils by requiring the Crown, under the Bourbons tax and financial intervention on the income of American churches.
\end{abstract}

Key words

Tithing - Quantitative sources - Bourbon Córdoba - Eighteenth century

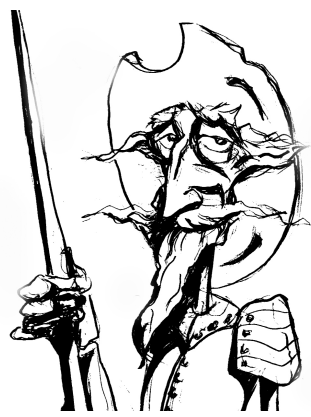

Recibido con pedido de publicación el 23 de marzo de 2016

Aceptado para su publicación el 5 de mayo de 2016

Versión definitiva recibida el 8 de junio de 2016

Élida María Tedesco, Facultad de Ciencias Sociales y Humanidades, Universidad Autónoma de San Luis Potosí, México; e-mail: elida.tedesco@uaslp.mx

\footnotetext{
* Agradezco los comentarios recibidos por parte de los evaluadores anónimos de la revista.
}

Tedesco, Élida María “Cuadrantes e informes para el estudio de las rentas decimales del obispado del Tucumán en el siglo XVIII", Prohistoria, Año XIX, núm. 25, jun. 2016, pp. 135-148. 


\section{Introducción}

Las catedrales coloniales centralizaban la organización del cobro del diezmo, su administración y distribución. Este estudio se ocupa de los documentos de las catedrales que registraban estas etapas de la práctica fiscal decimal. Específicamente de aquellos que brindan registros sobre el valor anual del diezmo de la catedral de Córdoba, obispado del Tucumán, en la segunda mitad del siglo XVIII. Se busca revisar la documentación decimal disponible y reflexionar sobre las posibilidades que brindan para un análisis cuantitativo. Puntualmente se indagan las actas del cabildo eclesiástico y los cuadrantes e informes sobre los montos de los ingresos decimales y su distribución, estos últimos, elaborados por el cabildo eclesiástico por exigencia de la Corona, en el marco del avance fiscal y financiero borbónico sobre las rentas de las iglesias americanas durante el siglo XVIII y primera década del siglo XIX. De este modo, se analizan las actas de sesiones del cabildo catedral de Córdoba de los años de 1788 a $1809^{1}$ y los registros cuantitativos sobre los diezmos del obispado del Tucumán conservados en el Archivo General de Indias (AGI), ${ }^{2}$ Archivo y Biblioteca Históricos de Salta (ABHS), ${ }^{3}$ y en el Archivo del Arzobispado de Córdoba (AAC). ${ }^{4}$

Los estudios sobre los diezmos del Tucumán se han visto dificultados por la escasez de fuentes con información cuantitativa sujeta de ser seriada. En este sentido, las investigaciones de Palomeque (2005 y 2008) ${ }^{5}$ y de Tell y Castro (2006 y 2008) ${ }^{6}$ son las que ofrecen las series más completas con los valores

\footnotetext{
1 TELL, Sonia Actas del cabildo eclesiástico. Obispado del Tucumán con sede en Córdoba (1802-1809), tomo III, Programa de Historia Regional Andina, Área de Historia CIFF y H-UNC, Ferreyra Editor, 2012,Córdoba; TEDESCO, Élida Actas del cabildo eclesiástico. Obispado del Tucumán con sede en Córdoba (1788-1801), Tomo IV, Programa de Historia Regional Andina, Área de Historia CIFFyH-UNC, Ferreyra Editor, Córdoba, (En prensa).

2 AGI, Indiferente, 2974; Buenos Aires, 598.

${ }^{3}$ ABHS, Gobierno, Carpeta nำ B.

${ }^{4}$ AAC, Legajo 19 y 21.

${ }^{5}$ PALOMEQUE, Silvia “Santiago del Estero y el Tucumán durante los siglos XVI y XVII, La destrucción de las tierras bajas en aras de la conquista de las tierras altas", en PALOMEQUE, et al., Actas del Cabildo eclesiástico del obispado del Tucumán con sede en Santiago del Estero, 1592-1667, Ferreyra Editor, Programa de Historia Regional Andina CIFFYH-UNC, Córdoba,2005, pp. 4575; “El Tucumán durante los siglos XVI y XVII. La destrucción de las 'tierras bajas' en aras de la conquista de las 'tierras altas'”, en Martini, Yoli; Pérez Zavala, Graciana y Aguilar, Yanina (comps.) Las sociedades de los paisajes semiáridos y áridos del centro-oeste argentino. Universidad Nacional de Río Cuarto, Río Cuarto, 2008, pp. 173-216.

6 TELL, Sonia y CASTRO OLAÑETA, Isabel "Actores, proyectos y conflictos en torno a la distribución de los diezmos en el obispado del Tucumán (siglos XVI y XVII), en Castro et al., Actas del cabildo eclesiástico del obispado del Tucumán con sede en Santiago del Estero, 1668-1699, Córdoba, Ferreyra Editor, Programa de Historia Regional Andina, 2006, pp. 21-57; CASTRO OLAÑETA y Sonia TELL, "La distribución del diezmo y sus conflictos en el obispado del Tucumán (siglos XVI y XVII)", en Folquer, Cynthia y Amenta, Sara (eds.), Sociedad, cristianismo y política. De la colonia al siglo XX, UNSTA, San Miguel de Tucumán, 2008, pp. 311-324.
} 
anuales de los diezmos del obispado para algunas décadas de los siglos XVI y XVII. Dichas series fueron construidas a partir de dos fuentes principales: un memorial de los arrendamientos de los diezmos, para la etapa 1590- 91 a 160001, y un documento del AAC con datos de recaudación a nivel de obispado, para la etapa de 1604-05 a 1616-17. Con estas cifras, Palomeque analizó los ingresos globales y comparados de los diezmos recaudados en las distintas jurisdicciones del Tucumán, tomándolos como un primer indicador de la ocupación territorial española, del movimiento de la producción agropecuaria y de la situación económica del Tucumán y de cada ciudad y su jurisdicción en los siglos XVI y XVII. Tell y Castro, por su parte, realizaron un estudio específico sobre la renta decimal, analizaron la normativa eclesiástica y real, su aplicación y los conflictos a que esta dio lugar en el obispado y que involucraron a la Corona y sus funcionarios, el obispo, el cabildo eclesiástico y la Compañía de Jesús. A partir de las cifras anuales del diezmo estudiaron la recaudación y sus fluctuaciones. Por otra parte, en los estudios de Garavaglia (1987), Arcondo (1992) y Mata de López (2000), sobre el siglo XVIII, encontramos el uso de las cantidades diezmadas como indicadoras la trayectoria de la producción agrícola ganadera del Tucumán. ${ }^{7}$ Por último, el estudio de Tell sobre la región de Córdoba ha tratado el tema del diezmo dentro de la esfera que le es propia, la de la fiscalidad, en tanto que se trata esencialmente de un impuesto o tributo. Tell analiza para la etapa 1750-1850 los posibles cambios en la forma de cobrar esta exacción que afectaba a la población rural. ${ }^{8}$

A este conjunto de trabajos el presente estudio busca aportar una descripción de las fuentes decimales disponibles para el obispado del Tucumán en la segunda mitad del siglo XVIII y la primera década del siglo XIX y avanzar hacia su crítica. Para ello se tiene en cuenta su carácter fragmentado, que fueron resultado de la particular organización administrativa de la catedral de Córdoba del ciclo decimal (remate para el arrendamiento de la recolección del diezmo, pago a la catedral de la cantidad convenida y reparto entre los beneficiarios) y el hecho de que la mayor parte de estos documentos fueron producto del avance fiscalizador borbónico sobre el diezmo. Este último punto se refiere al componente administrativo que se encuentra presente en las series

\footnotetext{
7 GARAVAGLIA, Juan Carlos "Crecimiento económico y diferencias regionales: el Río de la Plata a fines del siglo XVIII", en Economía, Sociedad y Regiones, Ediciones la Flor, Buenos Aires, 1987, pp. 13-64; ARCONDO, Aníbal El ocaso de una sociedad estamental, Dirección de Publicaciones de la UNC, Córdoba, 1992; MATA DE LÓPEZ, Sara Tierra y poder en Salta. El Noroeste argentino en vísperas de la Independencia, Diputación de Sevilla, Sevilla, 2000.

8 TELL, Sonia Córdoba rural, una sociedad campesina (1750-1850), Prometeo Libros, Buenos Aires, 2008, pp. 366-376.
} 
decimales construidas con las fuentes del siglo XVIII y cuyo efecto la historiografía recién comienza a identificar e intenta sopesar.

El análisis y la crítica de las fuentes cuantitativas de los diezmos americanos del siglo XVIII tienen particular relevancia para el empleo de las cifras resultantes en el estudio de temáticas destacadas como son crecimiento económico regional de las últimas décadas coloniales, el avance fiscalizador borbónico y los cambios que se produjeron en la economía eclesiástica colonial en esa etapa.

\section{Las fuentes decimales}

Los papeles decimales de las catedrales americanas fueron elaborados con fines fiscales, registrando las etapas de la práctica fiscal: el cobro, la gestión administrativa de la renta y el reparto de los rendimientos entre los partícipes. En los obispados donde se realizaba la recaudación directa del diezmo, la primera etapa se registraba en los llamados "cuadernos del diezmo", allí el colector asentaba el cobro o recaudación realizada en la jurisdicción decimal (diezmatorio, colecturía o administración), desde el registro de la siembra o crianza, pasando por la recolección, hasta la venta de los productos. Estos registros se componían de tres cuerpos documentales: el "cuaderno de manifestaciones", el "mapa" y el "cuadernillo". El primero era un libro certificado que la Contaduría de la catedral daba a cada colector, y en él se anotaban las declaraciones juradas de los productores sobre lo que esperaban obtener de sus siembras y crianzas, se especificaba el tipo de unidad productiva, el diezmo de indios, tipo de producción, la semilla sembrada, la extensión de la siembra y el nombre del dueño o arrendatario. El "mapa" constituía un resumen o registro general de todo lo recolectado en el diezmatorio, en partidas individuales según el tipo de producto, cantidad, calidad y precio (tasado por el recaudador). En el "cuadernillo" el colector anotaba las ventas del producto diezmado, el precio y lugar donde se vendía, las semillas que permanecían almacenadas, los costos de recaudación y venta (salarios, fletes, alquiler de trojes, etc.). ${ }^{9}$ Estos cuadernos eran entregados por el colector al cabildo catedral como comprobantes de su desempeño. A partir de la información que contenían, varios autores han construido series decimales, tanto en productos como en su valor de mercado, con el objetivo de conocer el movimiento de la producción agrícola en jurisdicciones pequeñas. Estas fuentes

\footnotetext{
9 La existencia de dichos registros y sus características ya han sido analizados en FLORESCANO, Enrique y Lydia ESPINOSA Fuentes para el estudio de la agricultura colonial en la diócesis de Michoacán: series de diezmos, 1636-1810, (2 vols.) INAH, México, 1987-1989 y en SILVA RIQUER, Jorge "Los registros decimales y su utilidad para la historia agraria colonial novohispana", en Fuentes para la historia económica. Boletín de fuentes, Instituto de Investigaciones Dr. José María Luis Mora, México, núm. 10, 1998, pp. 51-63.
} 
presentan interrupciones cuando la jurisdicción decimal, en lugar de ser confiada a un administrador nombrado directamente por la catedral, se otorgaba en arrendamiento mediante subasta. Bajo el régimen de arrendamiento el recaudador realizaba la recolección y venta de los productos decimales siguiendo su propio criterio y no tenía que presentar comprobantes, solo estaba obligado a cumplir cada año con el pago estipulado en el remate, durante el período de arrendamiento. En el obispado del Tucumán este fue el sistema de recaudación decimal empleado, mediante remates realizados en las ciudades principales del obispado se arrendaba la recolección decimal por periodos bianuales. En consecuencia, no es posible encontrar registros de los llamados "cuadernos del diezmo" para este obispado. Si es que los hubo para algunos años y jurisdicciones, no han sido conservados.

Otra documentación decimal de las catedrales era el registro contable de las fases de gestión administrativa y reparto entre los partícipes del ingreso decimal, la cual resulta útil para calcular los rendimientos anuales de la fiscalidad eclesiástica. Por un lado, porque en la tarea de reconstruir los ingresos decimales alcanzados por un determinado obispado es necesario considerar no solo los costos de recolección, almacenaje y transporte y venta (ya sea en los diezmatorios o en la ciudad), sino también los gastos administrativos y los descuentos a que podía estar sujeta la recaudación en las iglesias, cantidades que señalaba cuidadosamente la administración catedralicia en sus papeles. Por otro lado, porque entre los documentos de gestión y distribución elaborados por la administración de la catedral, en la Contaduría en particular, se encuentran resúmenes del procedimiento tributario decimal e informes sobre lo percibido por algunos de los partícipes del diezmo (obispo, cabildo eclesiástico, corona, hospital real, fábrica de la catedral). Los resúmenes, denominados "cuentas generales", "memorias" "sumarios" o "cuadrantes de repartimiento", ofrecen un cuadro global de las sumas entregadas por los colectores o arrendadores, los totales de gastos de recolección y venta, cuando corresponde, los costos administrativos y las rebajas que sufría la renta una vez ingresada en las arcas de la catedral y, finalmente, la distribución de los rendimientos entre los partícipes. Los informes, por su parte, proporcionan la relación de los montos anuales correspondientes a alguna de las porciones en que se dividía el ingreso decimal. ${ }^{10}$ Estos montos permiten estimar el total de

${ }^{10}$ En América, la división de los diezmos se realizaba entre el rey y los partícipes eclesiásticos. Primero, se dividían en cuatro partes, dos tocaban al prelado (cuarta episcopal) y al cabildo (cuarta capitular), respectivamente, de las otras dos partes se hacían nueve novenos, de los cuales dos pertenecían a su majestad, uno y medio a la fábrica de la iglesia catedral, uno y medio al hospital y los cuatro novenos restantes, llamados beneficiales, debían emplearse en el pago los salarios de los curas y acólitos de la catedral y de las parroquias (TEDESCO, Élida “Diezmo indiano: la fiscalidad eclesiástica frente a la ofensiva borbónica y la guerra de independencia (diócesis de México, Guadalajara y Michoacán, 1750-1821), Tesis, El Colegio de México, 2014, p. 199). No obstante la reglamentación general, en atención a la pobreza de 
los rendimientos del diezmo por tratarse de fracciones fijas de este, pueden solucionar así el problema de falta de datos completos para algunos años. ${ }^{11}$ Particularmente útil para estas estimaciones del valor total del diezmo resulta la porción perteneciente a la Corona (los dos novenos), porque no se encontraba gravada por pensiones, descuentos o gastos particulares, como las de los otros beneficiarios. $^{12}$

En el caso del obispado del Tucumán en el siglo XVIII, la documentación contable de la gestión decimal que se encuentra disponible se reduce a "Sumarios", "Certificaciones", "Cuadrantes de repartimiento" o "Informes" sobre el valor anual de las rentas episcopales y capitulares provenientes del diezmo. La característica central de estos documentos es que fueron producidos principalmente por exigencia de la Corona y con fines fiscalizadores. A continuación explico estas circunstancias.

\section{La exigencia de informes sobre valores recaudados, gestión y distribución de los diezmos}

Los Borbones, apoyados en la pretensión de un incuestionable dominio directo de la Corona sobre los diezmos de Indias, introdujeron disposiciones destinadas a proporcionar los medios para modificar la administración y la distribución del producto del impuesto eclesiástico. Muchas de las medidas fueron resistidas abiertamente o su eficacia aminorada por la inercia de las iglesias catedrales, no obstante, aseguraron hacia finales del siglo XVIII nuevos ingresos a la Real Hacienda.

algunas diócesis, la Corona permitió la partición de la masa decimal en tres. Esto sucedía en el obispado del Tucumán: la tercia del prelado, la del cabildo y una tercera fracción que se dividía en nueve partes o novenos. Estos nueve novenos se repartían de la siguiente manera: "cuatro para los rectores [curas de la catedral y de las iglesias de las principales ciudades de la diócesis] y beneficiados de las iglesias parroquiales, tres para fábrica y hospitales y los dos novenos restantes se reservaban al rey por el derecho de patronato". TELL y CASTRO OLAÑETA "Actores", cit., pp. 25-26.

${ }^{11} \mathrm{Al}$ respecto, MEDINA RUBIO señala que "es posible llegar a conocer el monto de la gruesa decimal a partir de cualquiera de las cuentas fraccionarias o parciales: de Cuarta episcopal, de cualquiera de las raciones o medias raciones, de los Novenos del Rey, del Noveno y medio del Hospital, Noveno y medio de la fábrica." La Iglesia y la producción agrícola en Puebla, 1540-1795, El Colegio de México, México, 1983, p. 35.

12 Pero debe advertirse que el uso de las porciones decimales de la Corona para reconstruir el valor anual de la renta decimal de una diócesis solo es posible a partir de las cifras provenientes de documentos eclesiásticos. No es correcto emplear los novenos que constan en los registros de las cajas de la Hacienda Real, pues se observa que las cantidades de los ramos "novenos reales" son muy abultadas en algunos momentos y muy bajas en otros, seguramente porque agrupaban los ingresos por novenos de varios años o de diferentes obispados. 
Este incremento de la presión de la Corona sobre la administración eclesiástica del diezmo en el siglo XVIII fue parte de un conjunto de disposiciones destinadas a fortalecer el control real sobre los institutos eclesiásticos americanos y sus patrimonios, esto último con el propósito de conseguir de las arcas eclesiásticas nuevos fondos para el fisco real. Estas exigencias borbónicas se dieron en el marco de un derecho de patronato ampliado y de una nueva concepción de América "como espacio de dominio colonial para el ejercicio del despotismo ministerial". ${ }^{13}$

En materia de diezmos, los funcionarios borbónicos consideraban la percepción de diezmos de Indias como una regalía y sus rendimientos como un ingreso más del Erario real, una vez atendidos el sustento del clero y las necesidades del culto. Sobre esta base doctrinal, propusieron que la Corona estrechara el control sobre la administración prácticamente autónoma que las iglesias ejercían del diezmo y sus rendimientos. El resultado fue una política crecientemente intervencionista de la Corona hacia el diezmo americano que comprendió numerosas disposiciones, desde intentar conocer y vigilar los niveles de recaudación hasta el despojar a obispos y cabildos eclesiásticos de la posesión en que se encontraban de ciertas porciones del diezmo, pasando por la recuperación de los dos novenos del rey, en la práctica cedidos a las fábricas de las iglesias catedrales, la exigencia de la efectiva distribución de los cuatro novenos beneficiales entre los párrocos de las diócesis, por la introducción de funcionarios reales en la contabilidad catedralicia y la imposición de impuestos reales a las rentas decimales. Pero, al inicio de este embate fiscal al diezmo indiano, los Borbones no conocían el monto de las rentas decimales de las diócesis americanas, hasta ese momento administradas de manera autónoma por los cabildos eclesiásticos en cada catedral. ¿Cómo gravar o intervenir el rendimiento de la fiscalidad eclesiástica si la Corona ignoraba cuánto producía y entre quiénes se repartía? Para remediar la ausencia de información decimal se enviaron a las catedrales de Indias reales cédulas solicitando se remitiesen al Consejo el estado de las rentas decimales, así como el sistema de reparto empleado y la estimación del valor de los ingresos proveídos por los beneficios eclesiásticos.

La real cédula de 1739 ordenó a los prelados y cabildos americanos remitir al Consejo de Indias, todos los años o por quinquenios, "relación puntual de todos los valores de los diezmos y demás obvenciones con que se hallaren y su distribución por menor" ${ }^{14}$ La reticencia o la excesiva demora de

\footnotetext{
13 GARRIGA, Carlos "Patrias criollas, plazas militares: sobre la América de Carlos IV", en MARTIRÉ, Eduardo (coord.), La América de Carlos IV (Cuadernos de Investigaciones y Documentos, I), Instituto de Investigaciones de Historia del Derecho, Buenos Aires, 2006, p. 5.

14 R.C. 11 julio 1739, en PURROY y TURRILLAS, Carmen Un libro inédito de Lebrón sobre diezmos en Indias, Universidad de Navarra, Pamplona, 1991, p. 29. La autora señala que en una real
} 
las iglesias para remitir las cuentas solicitadas obligaron a la monarquía a insistir continuamente con el cumplimiento de esta orden.

Las dilaciones interminables de algunas iglesias y la generalidad con que eran elaborados los informes que por fin se entregaban generaron la creciente frustración de los funcionarios en España. Allegarse de certificaciones minuciosas sobre el monto y distribución de los diezmos americanos había resultado una tarea lenta y de pobres resultados. De esto se quejaba en 1773 el contador general del Consejo de Indias al elaborar una relación de las rentas que "anualmente deben perzibir los reverendos arzobispos, obispos y cabildos eclesiásticos de las Yndias en la masa general de diezmos" con el objetivo de estimar la recaudación que resultaría de la imposición de la pensión de la nueva Real Orden de Carlos III. El contador expresaba que dicha relación se había "deducido de las escasas noticias que producen los citados repartimientos de algunas diózesis y formado presupuestos en otras [...] tal vez minorando la quota fija divisible por falta de una devida y exacta instrucción y conocimiento del positivo importe de los diezmos", pues aunque reiteradamente se han exigido estos cuadrantes, "no se ha verificado su cumplimiento en todas partes, por el empeño de los cabildos en ocultar las verdades, valores de diezmos y embarazar el aumento de prebendas o ymposición de pensiones" ${ }^{15}$

En 1766 el rey reconocía que con los informes que se habían recibido en obedecimiento de las reales cédulas de 1757 y 1759 "no se puede venir en conocimiento de las rentas que caben a las dignidades canónigas y demás prebendas de las mismas iglesias, asi por razón de diezmos y superávit de los quatro novenos", ni las rebajas hechas antes del repartimiento. Por este motivo, mandaba a las iglesias indianas enviasen los cuadrantes de los repartimientos de diezmos del último quinquenio $\mathrm{y}$, en adelante, los que se realizaran cada año. ${ }^{16}$

El carácter defensivo que demostraron las iglesias frente a las solicitudes de información alentó la introducción por parte de la Corona de funcionarios reales en la administración decimal catedralicia. En octubre de 1774 el rey privó a los cabildos catedrales americanos de la atribución que tenían de nombrar los contadores de diezmos y la reservó para sí. Con esta medida se introducían interventores reales en las rentas decimales de las iglesias metropolitanas y sufragáneas de las Indias. Los contadores de las catedrales eran los encargados del cálculo de la porción que correspondía a cada uno de los partícipes de la gruesa decimal.

cédula de 19 de marzo de 1734 ya se había ordenado el envío de la información decimal, pero al no ejecutarse se reiteró la orden.

${ }^{15}$ AGI, Indiferente 2973, "Relazion de las rentas que anualmente deven perzivir los reverendos arzobispos, obispos y cavildos eclesiásticos de las Indias en la masa general de diezmos de sus respectivas diócesis [...]", Madrid, 5 enero 1773.

${ }^{16}$ AGI, México, 2552, R.C. 25 febrero 1766. 
Según la real cédula, los nuevos contadores ejercerían las mismas funciones que los anteriores, tendrían iguales salarios y la obligación de asistir a los arrendamientos de diezmos junto a los oficiales reales, ministros del Tribunal de cuentas y jueces hacedores ${ }^{17}$. Además, serían los responsables de la elaboración y envío a la Contaduría general de los cuadrantes que año con año exigía la Real Cédula de 1765.

El origen de los documentos disponibles sobre el valor de los diezmos para el obispado del Tucumán en el siglo XVIII se encuentra principalmente en esta exigencia de información sobre los diezmos indianos por parte de la Corona y en el requerimiento de la entrega anual de los cuadrantes de repartimiento de la renta decimal, facilitados a partir de 1774 por la introducción de contadores reales de diezmos en las contadurías de las catedrales. De este modo, de la posible documentación sobre la recaudación, administración y reparto de los diezmos del Tucumán en el siglo XVIII, solo se conservan los informes sobre alguna porción de la renta o sobre los valores anuales y su reparto en un determinado quinquenio y los cuadrantes de repartimiento que los contadores reales de diezmos remitían como parte de sus funciones al Tribunal de Cuentas y/o a la Contaduría general del Consejo de Indias.

\section{Documentos decimales del obispado del Tucumán en la segunda mitad del siglo XVIII}

De los visto hasta aquí se desprende que para estudiar los montos y fluctuaciones de la recaudación decimal del obispado del Tucumán en el siglo XVIII las fuentes documentales son escasas y se restringen a sumarios, informes y cuadrantes dirigidos a la Real Hacienda. Es decir, del registro regular en las oficinas catedralicias de las etapas de arrendamiento, cobro y distribución de los diezmos no quedan testimonios.

Sobre otras posibles fuentes, al considerar las actas del cabildo eclesiástico para el siglo XVIII observamos que estas no brindan información de los montos comprometidos en los arrendamientos de diezmos ni de su distribución, ni siquiera hay registro del momento en que se realizan las subastas. Sobre los diezmos, las actas registran el nombramiento de los jueces hacedores y señalamientos cualitativos sobre el estado de las rentas decimales. Por ejemplo, en la sesión del cabildo catedral, del 26 de julio de 1796, se discutió la solicitud del contador de diezmos Juan Manuel López para que se aumentara la renta que recibía por su trabajo de 200 a 500 pesos, aduciendo "que hoy es

\footnotetext{
17 Los jueces hacedores eran capitulares responsables de organizar y controlar la recaudación/arrendamiento y administración de los diezmos.
} 
mucho mas laborioso y gravoso el empleo que obtiene y crecido el aumento que han tomado las rentas decimales". ${ }^{18}$

Así, para el obispado del Tucumán del siglo XVIII, la información decimal sujeta a ser seriada solo puede obtenerse de los ya mencionados informes y cuadrantes, resultado del avance fiscal borbónico sobre las rentas decimales. Puntualmente se localizaron en diferentes repositorios una certificación de los valores de las rentas decimales para 1738 y varios cuadrantes, relaciones e informes de la recaudación decimal y de su distribución para diversos años y quinquenios entre 1760 y 1807:

- "Certificación de la rentas decimales del Obispado del Tucumán 1738", AGI, Buenos Aires, 598.

- "Relación de lo que este obispado ha producido de las rentas dezimales en el quinquenio desde 1760-1765", AGI, Buenos Aires, 598.

- "Razón del producto de los diezmos de la provincia del Tucumán por el tiempo de cinco años que se regulan desde el veinte y quatro de junio del año de 1770 hasta el mismo día del año de 775. La prorrota de lo que ha tocado al reverendo Sr. obispo, cavildo y curas rectores", Córdoba del Tucumán, 29 abril de 1775. Archivo y Biblioteca Históricos de Salta, Gobierno, Carpeta nำ1 B.

- “Obispado del Tucumán. Diezmos. Quadrantes de ellos desde 1775 a 1780" y "Sumario de los estados del quinquenio que corre desde 24 de junio de 1775 hasta el mismo día y mes de 1780", AGI, Buenos Aires, 598.

- "Informe del obispo sobre los principales de diezmos, 14 de julio de 1782", AGI, Buenos Aires, 598.

- "Sumario de los estados del quinquenio que corre desde 1782 hasta 1786", AAC, Legajo 19.

- “Tucumán quadrantes de 1785-86 a 1792-93”, AGI, Buenos Aires, 598.

- "Prorrota de diezmos del año 85 al 87", AGI, Buenos Aires, 598.

\footnotetext{
${ }^{18}$ AAC, Actas de Cabildo, Libro 2, fs. 36v-37r.
} 
- "Córdoba del Tucumán, razon de sus diezmos de 1791-1792", AGI, Buenos Aires, 598; Indiferente, 2974.

- "Quadrantes y distribución de diezmos de la diócesis del Tucumán en el año de 1800-01 a 1806-07 [...] formados por el contador real de este reyno", AGI, Buenos Aires, 598.

Básicamente estos documentos brindan información sobre el valor de la recaudación decimal para el obispado y para cada jurisdicción y sobre el reparto entre los partícipes. Todos registran los valores anuales de los diezmos a nivel del obispado. Luego, en la mayoría ese valor anual se encuentra desagregado por jurisdicción decimal, es decir, muestra la recaudación del diezmo correspondiente a cada una de las siete ciudades de la provincia del Tucumán y sus jurisdicciones: Córdoba, Santiago del Estero, Tucumán, Salta, Jujuy, La Rioja y Catamarca. También dan, en general, el detalle de la distribución del diezmo recaudado entre los partícipes, mostrando el reparto por tercias de la gruesa decimal que se aplicaba en el obispado y la particular prórrota de los llamados cuatro novenos beneficiales entre los curas rectores de las iglesias sufragáneas y el personal de la catedral dedicado al culto.

Esta información sobre la forma en que se repartía el diezmo y los montos implicados aparece claramente reseñada en estos informes y cuadrantes, pues fue requerida insistentemente por la Corona, ya que buscaba intervenir para asegurar el correcto cobro de los dos novenos que le tocaban y evitar la centralización en las catedrales de los ingresos decimales que correspondían a fábricas, hospitales y novenos beneficiales. Por ejemplo, en uno de los cuadrantes se describe con detalle el cálculo de la porción del diezmo que tocaba a cada partícipe:

"Primeramente de el total se saca el tres por ciento para el Real Seminario; Ytem para el contador y escribano treinta pesos de cada ciudad; De la gruesa restante se hacen tres partes iguales; la primera para la silla episcopal; la segunda se reparte entre los cinco prebendados, dean arcediano, chantre, magistral y canónigo de merced dándole al primero veinte y cinco partes, al segundo y tercero a veinte y dos; y al quarto y quinto a veinte por la regla de proporción. De la tercera parte se forman 9 partes que se asignan a dos y media para los curas rectores de las matrices de las siete ciudades. A la fábrica de las mismas matrices una y media; dos a Su Magestad que entran en reales caxas; una y media al hospital que quitó y cedió Su Magestad en cedula de 17 de abril de 1774 a favor de la iglesia catedral; la una y media restante se distribuye entre los beneficiados menores, haciendo siete partes de las que se dan dos a los diáconos; de las otras cinco se forman tres, una para el capellan 
de coro, otra por mitad para los dos sacristanes maiores de la capital y la otra también por mitad para el sochantre y el organista" ${ }^{19}$

Los registros de los repartimientos también permiten conocer los gastos y descuentos que cargaba la gruesa decimal: el 3\% para el seminario, el sueldo del contador de diezmos y los pagos a "administradores" en las ciudades principales.

A partir de las cifras contenidas en estos documentos es posible construir series de los montos anuales de diezmos para el obispado y para las jurisdicciones de recaudación, así como de las rentas episcopales y capitulares y de lo que por concepto de dos novenos ingresaba a la cajas reales. Poseen la ventaja de tratarse de cifras homogéneas por pertenecer a un mismo tipo documental y, por lo tanto, comparables.

Además, permiten conocer la estacionalidad del ciclo decimal del obispado del Tucumán. Es decir, el lapso de tiempo que demandaba el otorgamiento del arrendamiento de los diezmos, la efectivización del pago por el arrendador y el reparto entre los partícipes de la renta decimal. En este caso, se realizaba en cada ciudad del obispado el remate de los diezmos de esa ciudad y de su jurisdicción por dos años a contar de san Juan a san Juan, es decir, de 24 junio a 24 de junio, "a pagar por mitad al año". El repartimiento del diezmo se realizaba cuando el arrendador realizaba los pagos correspondientes en junio de los dos años siguientes. ${ }^{20}$ Este sistema de recolección por arrendamiento del obispado del Tucumán daba ciclos decimales prácticamente anuales, diferente a los de las diócesis que optaban por la recaudación directa, los cuales podían durar hasta tres años. ${ }^{21}$ Conocer la estacionalidad del ciclo decimal permite relacionar con mayor precisión las fluctuaciones de los montos anuales de recaudación con variables de la economía regional, con circunstancias meteorológicas que afectan las cosechas o con cambios en los precios.

Entre los límites de estas fuentes debemos señalar su carácter fragmentado, que impide la reconstrucción de la recaudación decimal del Tucumán en el largo plazo. Solo se dispone de información para los siguientes periodos: 1738; 1760 a 1765; 1770 a 1775; 1782 a 1793; 1800 a 1807. Siempre teniendo en cuenta que el año decimal comprendía de junio de un año a junio del siguiente.

Otra cuestión a tener en cuenta sobre estas fuentes es que no ofrecen información sobre la composición de los diezmos, es decir, sobre qué productos se cobraban, que proporción de estos conformaba la recaudación, qué unidades

\footnotetext{
${ }^{19}$ AGI, Buenos Aires, 598, “Quadrantes del Tucumán 1775 a 1780".

${ }^{20}$ AGI, Buenos Aires, 598, "Prorrata del año 86 al 86".

${ }^{21}$ Este era el caso del obispado de Michoacán en la Nueva España.
} 
de producción se encontraban gravadas y, por lo mismo, si hubo cambios a lo largo del tiempo en estos componentes. Por lo tanto, nos dicen poco sobre la producción agropecuaria regional. Solo pueden considerarse un primer indicador del movimiento general de la producción española que debe complementarse con otras referencias. Más aún si tenemos en cuenta que la recolección se arrendaba, con lo cual los cambios en la producción tardarían más en reflejarse en los montos recaudados, pues su variación dependía del ajuste del valor del arrendamiento por parte del cabildo eclesiástico y no directamente del aumento o disminución del volumen de la producción.

En relación con lo anterior, un problema central de las cifras obtenidas de estos documentos es que representan los ingresos globales anuales por diezmos de la iglesia del Tucumán expresados en moneda corriente del periodo. Por tanto, las series construidas a partir de estos datos reflejarán al mismo tiempo los cambios del volumen físico de la producción, las variaciones de los precios y los cálculos de beneficio de los arrendatarios de los diezmos. ${ }^{22}$

Lo deseable sería corregir las series de diezmos con el uso de un índice de precios. Esto permitiría, por ejemplo, identificar los puntos máximos concomitantes con carestías que se transformarían en puntos mínimos o conocer cuánto de la pronunciada tendencia ascendente de los ingresos decimales a finales del periodo colonial corresponde a un incremento sostenido de los precios. Lamentablemente, no se dispone de índices de este tipo para el espacio y la época estudiados. ${ }^{23}$

Un último elemento a considerar es el componente institucional de estos documentos. Sabemos que son resultado del incremento de la presión fiscal de

\footnotetext{
${ }^{22} \mathrm{Al}$ respecto, Joseph Goy advierte que no es posible asumir directamente una correlación entre cada movimiento de alza o baja de la curva de diezmos basada en valores en dinero y los niveles de producción, pues intervienen otros factores como los cambios institucionales y los precios. "Methodology", en Emmanuel Le Roy Ladurie y Joseph Goy Tithe and Agrarian History from the Fourteenth to the Nineteenth Centuries. An Essay in Comparative History, tr. Susan Burke, Cambridge University Press, Cambridge, 1982, p. 28.

${ }^{23}$ El mismo Goy señala las dificultades que presenta construir un índice que permita deflactar estas series de diezmos en dinero, pues se basan en la combinación de productos: esto implicaría usar un índice compuesto, derivado de los precios de los principales productos de cada jurisdicción fiscal y calculado de acuerdo a las proporciones de cada producto que compone el diezmo. Empresa "imposible" a partir de la información que refieren los documentos del diezmo en moneda. Teniendo en cuenta esto, el autor propone como alternativa el uso de un índice de precios basado en los precios de los granos, ya que estos son el mayor elemento en la producción y consumo. "Methodology", pp. 43-51. A pesar de las dificultades planteadas, algunos autores han realizado la corrección o "deflación" de curvas de diezmos por medio de índices de precios basados en los principales productos agrícolas, con el objetivo de mostrar el movimiento de la producción real en un determinado espacio: CARMAGNANI, Marcello Les mécanismes de la vie économique dans une société coloniale: le Chili (1680-1830), Paris, 1973 (en español, 2001); TANDETER, Enrique y WATCHEL, Nathan Precios y producción agraria. Potosí y Charcas en el siglo XVIII, Estudios CEDES, Buenos Aires, 1984.
} 
la Real Hacienda sobre las rentas decimales americanas, presión que pudo trasladarse a los contribuyentes del poder fiscal eclesiástico a través de mayores esfuerzos de las catedrales por controlar la evasión y resistencia al pago de los contribuyentes o mediante la actualización continua del valor de los arrendamientos. Además, a partir de la introducción de contadores reales en las oficinas catedralicias en1774, el registro de los valores de diezmo en estos informes que se enviaban a la Corona se estandarizó para todas las iglesias americanas, con las posibilidades comparativas que esto ofrece. Conocer si el trabajo de los contadores tuvo algún efecto en la tendencia de los valores anuales del diezmo requiere avanzar hacia un mayor conocimiento de las formas contables de las catedrales anteriores a la ofensiva borbónica para establecer posibles diferencias, lo cual resulta dificultoso en el caso del Tucumán por la escasez de fuentes decimales.

Para terminar, lo revisado hasta aquí pone de relieve la importancia de realizar una cuidadosa crítica de fuentes a la documentación decimal del siglo XVIII. Las características particulares de los tipos documentales disponibles, como el contexto de presión fiscal borbónica del que surgieron, remarcan la necesidad de establecer una imprescindible reflexión sobre los alcances y límites que presenta el empleo de estas fuentes decimales cuantitativas. Esfuerzo ineludible porque el valor de las cifras de diezmos para el mejor conocimiento de problemáticas centrales del pasado colonial, como son el comportamiento de las economías regionales, el avance fiscalizador borbónico y el devenir de la economía eclesiástica, obliga a no desatender su reconstrucción y empleo, a sabiendas de que las cifras obtenidas de estos informes o cuadrantes de repartimiento no serán un reflejo directo de la producción, pero si un primer indicador del movimiento general de la base de imposición del impuesto decimal, que es la producción agropecuaria, y que dichas cifras deben ser puestas en diálogo con otras fuentes. Finalmente, que los valores de los diezmos nos pueden ayudar a conocer las fluctuaciones de la recaudación fiscal de las catedrales y con ello valorar los cambios en la economía eclesiástica en un momento de asedio de la Real Hacienda, como fue el siglo XVIII. 